\title{
Erratum: Numerical investigation and experimental test on aerodynamic noises of the bionic rear view mirror in vehicles
}

\author{
Jing Wan ${ }^{1}$, Lei $\mathrm{Ma}^{2}$ \\ ${ }^{1}$ School of Architecture, Southeast University, Nanjing, China \\ ${ }^{2}$ School of Electronic Information, Nantong University, Nantong, China \\ ${ }^{2}$ Corresponding author \\ E-mail: ${ }^{1}$ dupihedubao@163.com, ${ }^{2}$ mlmyhero@163.com \\ DOI https://doi.org/10.21595/jve.2019.21208
}

Check for updates

Copyright (C) 2020 Jing Wan, et al. This is an open access article distributed under the Creative Commons Attribution License, which permits unrestricted use, distribution, and reproduction in any medium, provided the original work is properly cited.

\section{Publisher's note regarding paper}

Wan Jing, Ma Lei Numerical investigation and experimental test on aerodynamic noises of the bionic rear view mirror in vehicles. Journal of Vibroengineering, Vol. 19, Issue 6, 2017 , p. 4799-4815, https://doi.org/10.21595/jve.2017.18750.

\section{The description of the correction}

The corresponding author number was set incorrectly in the paper finally approved (after the acceptance) by the authors.

Incorrect corresponding author number:

${ }^{1}$ Corresponding author

Revised corresponding author number:

${ }^{2}$ Corresponding author 